behind the sigmoid flexure-i.e., through the mesosigmoid at $x$. This coil of small intestine, finaing insufficient room towards the left, turned again towards the middle line in front of the sigmoid flexure, contracting adhesions to the parietal peritoneum near to, or at the line of, the previous laparotomies. It will therefore be seen that the coil of small intestine not merely passed beneath but formed a complete and fixed loop round the sigmoid flexure. This condition of potential danger must have existed for some time, since the adhesion between the constricting loop and the parietes was one of well organiced tissue. We have only to invoke some vigorous peristaltic action with, perhaps, some flatulent distension of the colon and it becomes easy to imagine the supervention of acute obstruction. In conclusion, I wish to add that the successful issue of this case must be entirely attributed to the early diagnosis of intestinal obstruction and determination for operation arrived at by both the patient and Dr. House who first saw him.

Torquay.

\section{OBSERVATIONS ON MASTICATION.}

By H A R R Y CA M P B E L L, M. D., F. R C.P. Lond., PHYSTCIAN TO THE NORTH-WEST LONDON HOSPITAL.

\section{II. ${ }^{1}$}

Changes which the Jaws and Teeth of MaN have UNDERGONE DURING MAN'S EVOLUTION FROM HIS

\section{ANTHROPOID ANCESTORS.}

DURING man's progress upwards from the anthropoid his diet has undergone a progressive change and a parallel adaptation has taken place in his jaws and teeth. Dietetic ally considered we may divide his evolutionary career into the following epochs ${ }^{2}$ : (1) the anthropoid stage; (2) the pre-cooking human stage; (3) the cooking pre-agricultural stage; (4) the early agricultural stage; ard (5) the late agricultural stage.

1. The anthropoid stage.-The diet of man's anthropoid ancestors was probably much the same as is that of existing anthropoid apes ; it consisted, namely, of raw vegetable and animal food, necessitating a vigorous use of the maxillary apparatus. This latter we may assume was of the type belonging to the anthropoids-i.e., the jaws were massive and markedly prognathic ; the denture was the same as it is in existing man, but the teeth were larger, especially the upper canines, which served as weapons of offence and defence; the third molars (the wisdom teeth) were as large as the other molars and were provided with three fangs, and there was an ample portion of alveolar ridge behind them; there was no chin. No doubt the massiveness and the marked prognathism which characterised the jaws at this stage served other ends than that of mastication; it is obvious that projecting jaws and teeth are much more effectual for seizing and lacerating prey than are the orthognathic jaws of modern man.

2. The pre-cooking human stage extends from the time man's ancestors first assumed the human form till they learned to apply fire in the preparation of their food. During all this period the jaws and teeth were vrobably used as much, or almost as much, for mastication as during the anthropoid stage; raw animal tood had to be torn from the bones, the latter had to be crunched, while the bulk of the raw vegetable food needed then no less than it needs now prolonged and vigorous mastication in order to liberate the starch and other nutritive ingredients from their undigestible cellulose envelopes. ${ }^{3}$ Nevertheless, the jaws and teeth underwent considerable change during this period, for not only were they with every advance in intelligence called less and less into requisition for purposes of offence and defence, but the jaws, at least, became materially modified in correlation with the expanding cranial cavity and in connexion with the assumption of the erect posture. It is, I think, rather for these reasons than in consequence of alterations in the nature of the food that the masticatory apparatus now

1 No I. was published in The LANCET of Jaly 11th, p. 84.

2 This subject I am obliged to deal with very briefly and am compelled to omit the reasons for my conclusions.

3 Recent observations go to show that man possesses no power of digesting cellulose, though this substance is to a limited extent capable of solution by the agency of bacteria in the lower portions of his alimentary canal. gradually lust its more bestial aspect and asiomed an essentially human type, becoming towards the close of the period much the same as may be observed among the most primitive peoples now living.

3. The pre agrioultural cooking period. - The characters of the maxillary apparatus belonging to this period are still available for study, the aboriginal Australianc, the Bushmen, Negritos, and many Esquimaux not having yet emerged from it. So far as mastication is concerned, cooking influences vegetable far more than animal food, for it not only softens it but by rupturing the undigestible cellulose chambers and liberating their contents relieves mastication of one of its essential functions. Wherefore with the advent of cooking man's jaws and teeth began to get smaller and they have continued to diminish in size up to the present time. No great diminution, however, took place at first, inasmuch as the diet still continued to be largely animal (and prior to the use of knives and forks such food had to be torn by the teeth), while the coarse vegetable food of this date, even when cooked, still needed laborious mastication. The chief differences between the maxillary apparatus of this early cooking age as compared with that of the present day are as follows: the jaws of the earlier period-e.g., in the aboriginal Australian-are more massive and their sagittal diameter is greater, giving rise to decided prognathism, the teeth for the most part are larger and stronge $r$, the third molars being nearly, if not quite, as big as the other molars and provided with three fangs, while there is a considerable portion of alveolar ridge behind them. The third molars, however, show a decided tendency to be smaller than the rest and the alveolar ridge behind them is less marked than in the previous period, features, I doubt not, attributable to the influence of cocking in diminishing mastication. Dental caries is rare and is chiefly met with in the third molars.

4. The early agricultural age.-All the existing primitive races which have attained to the cultivation of the soil may be regarded as belonging to this period. Previously to it man was mainly carnivorous, owing to the comparatively limited quantity of vegetable food available so long as the supply was left to nature alone, but when by cultivation this supply was increased and at the same time rendered more constant and certain he gradually became less carnivorous and more vegetarian in his diet. The result of agriculture, however, is not only to increase the supply of vegetable food but to diminish its fibrous, cellulosic ingredients and thus to renderit more easily masticated. Hence at this stage we find the maxillary apparatus becoming smaller than in the previous period, although the difference as shown-e.g., by the examinations of the skulls of the African negroes and the Melanesians-is less pronounced than we might perhaps have anticipated; prognathism is not so decided, the jaws are smaller, also the teeth, especially the third molars, which now for the first time show a tendency to be furnished with two instead of three fangs, while the alveolar ridge behind them is distinctly shorter than in the preceding period. Dental caries, hitherto rare, now becomes more frequent.

5 The late agricultural period.-A mid-agricultural period might be described, but I shall take no account of it here but pass on to a consideration of the late agricultural periodthat, namely, in which we ourselves live. The chief characteristic of the food of this period is its softness. Cooked animal food requires, indeed, more mastication than raw, but the vegetable food of to.day, owing to the combined effects of improved agriculture and skilful milling and cooking, is so soft as to excite comparatively little mastication. The present may, in fact, be described as the age of pap. Hence the jaws and teth are now called upon to perform tar less work than in any earlier stage of our evolution and there has taken place in consequence a great diminution in their size, more especially in the size of the jaws, so that there is now often no room for the teeth to take up their normal positions and there is generally a complete absence of alveolar ridge behind the last molars. The latter are, moreover, apt to be very small or even absent, while dental caries is alarmingly frequent.

It will thus be seen that from the period of the anthropoids to the present time a progressive change in the size and shape of the jaws and teeth has been taking place, a change which is to be explained by (1) the cessation of the need for using them for offensive and defensive purposes; (2) the growing capacity of the cranium and the assumption of the erect position; (3) the progressive alteration in man's diet and probably also (4) considerations of beauty. The first 
three factors have operated through natural selection, the last through sexual selection, which has come into play, I would suggest, chiefly within recent times. Probably the most pronounced change which has taken place in the jaws during the agricultural periods has been the suppression of prognathism which, in the woman especially, is very unsightly and tends to diminish the likelihood of marriage.

Instances OF THE Vigorous Use TO WHich THE JAWS and Teetr are pUt among Existing Primitive

\section{Phoples.}

A study of existing primitive peoples brings forcibly home to the mind how laboriously the jaws and teeth of our primitive ancestors were used. I have already shown how in pre-agricultural and early agricultural times the nature of the food compelled a sustained and vigorous exercise of these structures and I wirh here only to refer to a few specific and peculiar instances of laborious mastication exercised by primitive races now or recently living. ${ }^{*}$ Among some of these mastication has been promoted almost to the position of an industrial art.

The chewing of very tough substances in order to extract therefrom liquid or nourishment. - The recently extinct Tasmanians included among their articles of diet a species of sea-weed which even when cooked was so tough as to require long-sustained mastication in order to extract its nutrient elements. The Indians of North California chew kelp which is "as tough as white leather" (i.e., leather dressed with alum). "A young fellow with good teeth will masticate a piece of it a whole day." Again Featherman ${ }^{5}$ tells how when the Bushmen are short of food in the winter they steep an old dried gnu-skin in water and, having rubbed off the hair, boil it and proceed to gnaw the tough morsel until their very jaws ache. The Modoc Indians are said to munch the raw kais root all day long. ${ }^{6}$ Among the Esquimaux it is a universal custom to chew the raw skin of the whale, the porpoise, and the seal for the blubber it contains, and the skin being as tough as india-rubber it requires, as may be imagined, a good deal of chewing. The Lower Californians also chew deer-skin and ox-skin (Bayert). The more southern Esquimaux, according to Nansen, preserve the stalks of angelica by steeping them in a mixture of chewed blubber and saliva. Finally, I may refer to the habit of chewing the sugar-cane, a practice which is prevalent among the natives in all countries where the cane grows and affords, it need scarcely be said, abundant exercise for the jaws and teeth.

Mastication in the preparation of beverages.-I find that among widely separated aboriginal peoples chewing is resorted to in the preparation of beverages, both intoxicating and non-intoxicating. The Gran Chaco Indians make an intoxicating drink by chewing the algarroba bean and then spitting into a receptacle. In other parts of South America berries are chewed with the same object. In some of the Pacific Islands boys and girls with good teeth are selected to chew a root (kava) from which they then prepare a drink. In New Guinea drinks are similarly prepared from roots. Boiled cassava root is chewed by the Indians of Nicaragua for the same purpose. In British Guiana the natives make a drink by adding chewed maize and saliva to sweet potato, maize, and sugar-cane. The Indians in Honduras, after steeping cassava cake or carbonised bread in hot water, chew a vortion and mix it with the rest.

Mastication in the industries.-Even among moderns teeth are used for many purposes other than mastication-e.g., for holding pins and needles and for severing cotton; also in some industries-e.g, among diamond workers-where it is the custom for girls to hold the diamond between their front teeth. which in consequence get much worn away, as I have myself seen. It is only among primitive peoples, however, that the jaws and teeth actually play the part of implements for use in the arts. The Australian women make lines, nets, and bags by chewing various kinds of fibre, a process which wears down their teeth considerably and may cause them to be tender ${ }^{7}$ The Esquimaux are still more dependent upon the use of their teeth as implements, especially in the preparation of skins for their clothing, boats, and lines. The teeth are

4 I am under great obligation to Miss Eva Dunn, who has collected valuable information for me on this and kindred subjects. Social History of the Races of Mankind, 1881 S. Powers : Tribes of California, 1877

7 E. M. Curr: The Australian Races, 1886-7. Taplin : The Narrinyeri : an account of Tribes of South Australian Aborigines, 1879. used to hold the skins while the latter are being scraped, the mouth constituting in fact "a third hand," and the front teeth of Esquimaux women are often by this means worn away to the merest stumps. ${ }^{8}$ The garments of the Esquimaux even to the boots are made up of skins which have been laboriously chewed for this purpose by the women "inch by inch" till they acquire a beautiful softness and flexibility and are often indeed chewed again after having been dried. And we are told that the women have no objection to the task, while the children are eager to help in it on account of the blubber the skin contains; also, that in bad times the men do not object to join in the work. The lines for harpooning are prepared in a similar way from the skin of the bearded seal and in very large quantities. ${ }^{9}$ When we think of the quantity of skins needed for these lines, for their dress, including boots and gloves, and for their boats (although for the latter some skins are used without having first undergone chewing), it is clear that enormous quantities must be chewed. The fisquimaux men also use their teeth considerably in other work-e.g., in lashing the sledges together. ${ }^{10}$ The Indians of North California use their teeth for stripping the bark from the fresh shoots employed in making their wickerwork utensils and they also employ their teeth in making strings, cords, and nets.

The Instinct to Masticate.

Seeing that the maxillary apparatus of man has for long ages past been put to vigorous use it is not surprising that the need to exercise it should express itself as a powerful instinct. This instinct manifests itself in many and curious ways, some of which I will now consider. During the early months of life the natural function of feeding at the breast provides the infant's jaws, tongue, and lips with all the needful exercise. This bottle-feeding fails to do, and we frequently find bottle-fed children seeking to satisfy the natural instinct by sucking their thumb, fingers, or any convenient object to hand. The teeth are a provision for biting hard foods but even before they actually appear we find the child seeking to exercise his toothless gums on any hard substance he can lay hold of, and there can be no doubt that exercise of this kind tends to facilitate the eruption of the teeth, a truth, indeed, recognised universally, whether by the primitive mother who strings the tooth of some wild animal round the neck of her infant, or the up-to-date parent who provides her child with a bejewelled ivory or coral bauble. When the teeth have erupted the masticatory instinct finds among primitive peoples abundant satisfaction in the chewing of the coarse, hard foods which constitute their dietary; but among us moderns, subsistirg as we do mainly on soft foods, affording but little exercise for the masticatory apparatus, it does not find its proper 6 xpression, and thus tends to die ont. Nevertheless, it dies a hard death and long continues to assert itself; witness the tendency of children to bite their pencils and pen-holders ; I Lave known a child to gnaw through a bone pen-holder, much in the same way as a carnivorous animal gnaws at a bone.

This instinct to chew for chewing's sake manifests itself all over the world. In our own country not only do children bite pencils and pen-holders but they will chew small pieces of indiarubber for hours together. The practice of gumchewing, so common among our American cousins, evidently comes down from far-off times, for the primitive Australians chew several kinds of gum, attributing to them nutrient qualities, 11 and the Patagonians are said to keep their teeth white and clean by chewing matri, a gum which exudes from the incense bush and is carefully collected by the women and children. ${ }^{12}$

A widespread custom in the Kast is betel-chewing which is met with in India, Malay, Melanesia, and Polynesia, and even among the primitive Veddahs of Ceylon. This article is composed of the pungent leaf of the betel plant, the areca nut and lime rolled together, and when chewed yields a reddish juice which stains the mouth and teeth. The Veddahs, failing to get the genuine article, manufacture a quid from the leaves of an aromatic plant, the barks of one or two kinds of tree, and calcined small shells. ${ }^{13}$ The compound must possess some strange attraction, for otherwise such pains would not be taken to secure it. What is the

8 J. F. Nansen : Eskimo Life. 1893.

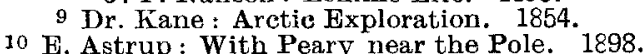

11 Sir Gecrge Grey: Journal of Two Expeditions in North-West and Western Australia, 1841.

12 Muster: With the Patagonians. 1869. 
attraction? Doubtless betel has stimulating properties and it must, moreover, be remembered that the mere mechanical act of mastication stimulates the circulation, a fact which helps to explain the tendency for man, all the world over, to chew non-nutrient substances. Tobacco-chewing is common in many parts of the world and here, again, the effect for the time is stimulating. Pitcherie is extensively chewed among the aboriginal Australians; it consists of twigs of about the thickness of rye-grass stems, which are first chewed into a mass, then mixed with the ash of gum trees, and made into a paste which is chewed for its stimulating and narcotic effects. ${ }^{14}$

I may allude in passing to the grinding of the teeth which takes place during sleep in disturbed states of the nervous system. It is a true masticatory act in which the normal lateral movement of the mandible is well marked and it may thus be regarded as a perverted manifestation of the masticatory instinct.

\section{The Causation of Inefricient Mastication.}

The effects for good upon the organism of efficient mastication being profound and far-reaching it follows that inefficient mastication must lead to many evils. What these are we have now to consider, but first it will be well to inquire into the causes of the defective mastication which prevails among moderns.

1. Softness of food. - By far the most important of these lies in the nature of the food taken. The food of to-day-of the late agricultural age period, as I have termed it-is for the most part soft and pappy, of a kind which does not compel thorough mastication; so much so indeed that, as I have already said, we may speak of this as the age of pap. This feature is especially noticeable in the case of children's diet : under the modern system children are kept on a liquid, or semi-liquid, diet not merely during the first months but during the first years of life, and at the seventh or eighth month all kinds of artificial saccharide foods in liquid or semiliquid form are poured into the child's stomach; thereafter he is fed on such viands as mashed potatoes and gravy, rusks soaked in milk, milkpuddings, bread dipped in bacon fat, pounded mutton, thin bread-and-butter, and the like; and we are told that this is the kind of diet best suited to the young human, from the time of weaning to the end of the second year $!$ The same pernicious methods are adopted subsequently. "'Perhaps the great majority of children after they have got their complete set of temporary teeth have," writes Dr. Sim Wallace, ${ }^{15}$ "a dietary such as the following. Breakfast: bread-and-milk or porridge, milk, tea, coffee, or cocoa, bread-and-butter, perhaps an egg. Dinner: potatoes and gravy, or meat, milk pudding. Tea: milk or tea with bread-and-butter, jam, cakes. Supper : bread or biscuit and milk." Now food of this kind does not invite mastication and it finds its way into the stomach all too readily. Hence the instinct to masticate has little opportunity of exercise and not being properly exercised tends, as I have said, to die out. Small wonder that the child nourished on such pappy food acquires the habit of bolting it and learns to reject hard, coarse foods in favour of the softer kinds ; everything nowadays must be tender, pultaceous, or "short." Given a choice between a food compelling little or no mastication and one necessitating prolonged mastication-as between, say, fresh Vienna bread and an Abernethy biscuit-and in 19 cases out of 20 the one which gives the least trouble in eating will be chosen. To such absurd lengths has this harmful custom been pushed that even bread-crust is avoided by many. Witness the fashion of eating bread-and-butter with 2 minimum of crust; order bread-and-butter at any place of refreshment and the last thing you will be served with is a plateful of crusts of bread. Many establishments, indeed, make a regular practice of giving away their crusts as unsaleable. Thus, the rectangular loaves used for bread-and-butter in the "Aerated bread shops" are cut transversely into slices, each loaf thus yielding two end crusts which are put into baskets for the poor, only the soft crumby pieces being reserved for the customers, to be in due course no doubt washed down by copious libations of tea and coffee.

When we trace the diet of the modern from childhood upwards we find the same story: it tends to remain

If E. M. Curr : The Airstralian Race. 1886-87. 15 The Causes and Prevention of Decay in Teeth, pp. 88, 89. London, $15 \mathrm{~T}$ soft and pappy to the end.

Animal food, especially as well-to-do, necessitates If is the coarser varieties of vegetable food alone which call out the full functional activity of the masticatory apparatus, but the vegetable food of to-day is rarely of a kind to do this; cooked vegetables, such as potatoes, greens, peas, and beans, can be, and generally are, swallowed after little or no preliminary mastication, and our flour is so carefully deprived of its fibrous portions and so cunningly dealt with in the bakehouse and kitchen in the making of bread, cakes, and pastry which shall eat light and short that these articles get very little chewing; while such vegetable products as rice, vermicelli, tapioca, and macaroni are, as served at table, so soft that they slip down into the stomach almost as readily as simple milk. Let anyone run through his dietary of any one day and he will realise how very little work his masticatory apparatus is called upon to perform. It will read something like the following. Breakfast : porridge and milk, eggs, bacon, bread, and marmalade. Lunch : fish, tender meat, boiled vegetables, bread, some "sweet," and cheese. Tea: bread, butter, and cake. Dinner : much the same as lunch. What opportunity, I ask, does such a bill-of-fare afford for the development of teeth and jaws and for the proper functional activity of the salivary glands?

2. Defeotive masticatory apparatus. - Another potent cause of inefficient mastication is some defect in the masticatory apparatus and defects of this kind are very common in those who have not been accustomed to masticate thoroughly in early life. Foremost among these are irregularities of the teeth leading to faulty "bite" and caries of the teeth which causes them to be tender or to break away, if it does not lead to their actual extraction. Mastication cannot be thorough where the bite is defective, for this not only leads to imperfect opposition of the upper and lower teeth, but renders the lower ones incapable of that ample lateral movement against the upper which is needful to normal mastication.

3. Idiosynorasy. - Some are temperamentally more disposed to hurry over their meals than others. The katabolic, restless, nervous individual is more apt to swallow his food hastily than is his more deliberate and phlegmatic brother. Individual differences in this respect are even observed among the lower animals. Thus, one of a pair of horses of about the same age and build is nervous and excitable and inclined to bolt its food. while its companion of more stolid temperament is a thorough and efficient masticator. The former shows comparatively little wearing down of the teeth and often suffers from indigestion, a large portion of corn grains passing through his digestive canal intact; in the latter the teeth are well worn, indigestion never occurs and but very few grains pass through the digestive tract unchanged. It may be objected here that we cannot help temperament and to a large extent this is true, but much can be done towards modifying it, and it is something to know where dangers, temperamental dangers among others, lie.

4. Circumstances of life.-Again in this hurrying, strenuous age people are much less deliberate than in the easy, slowgoing days of long ago. A meal is too often regarded as something to be got through quickly, as taking up time which might be devoted to something more profitable. Especially is. this true of breakfast and lunch; it is no uncommon thing for a business man to hurry through his breakfast in a few minutes preparatory to rushing off to his train, and his lunch as likely as not is as hastily swallowed in his office or at a bar. Tradesmen are apt to take their meals in mere snatches; apprentices, shop girls, and other " "hands" are often not allowed sufficient time for their meals while, to come to the professions, we all know how the busy medical man, for instance, is often obliged to take a hurried snack in the short intervals between seeing his patients. No wonder that thus circumstanced people acquire the habit of bolting their food. A meal should be regarded as an end, and an important end, in itself. It should be taken at leisure, body and mind being for the time being given up to it and to agreeable social intercourse. If this rule were always observed a most important source of ineflicient mastication would be removed.

(To be continued.)

AT the quarterly meeting of the directors of the Naval Medical Supplemental Fund held on July 14th, Sir J. N. Dick, K.C.B., in the chair, the sum of $£ 50$ was distributed among the several applicants. 